Revue

Revue de l'histoire des religions

de Ihistoire des religions

$1 \mid 2016$

Varia

\title{
Victor I. STOICHITA, Figures de la transgression
}

Genève, Droz (« Titre courant », 51), 2013

\section{Alberto Frigo}

\section{OpenEdition}

\section{Journals}

Édition électronique

URL : http://journals.openedition.org/rhr/8537

DOI : $10.4000 /$ rhr.8537

ISSN : 2105-2573

\section{Éditeur}

Armand Colin

\section{Édition imprimée}

Date de publication : 1 mars 2016

Pagination : 146-148

ISBN : 978-2-200-93059-2

ISSN : 0035-1423

Référence électronique

Alberto Frigo, «Victor I. stoıснітA, Figures de la transgression », Revue de I'histoire des religions [En ligne], 1 | 2016, mis en ligne le 05 avril 2016, consulté le 23 septembre 2020. URL : http:// journals.openedition.org/rhr/8537; DOI : https://doi.org/10.4000/rhr.8537

Ce document a été généré automatiquement le 23 septembre 2020

Tous droits réservés 


\title{
Victor I. STOICHITA, Figures de la
}

\section{transgression}

Genève, Droz (« Titre courant », 51), 2013

\author{
Alberto Frigo
}

\section{RÉFÉRENCE}

Victor I. STOICHITA, Figures de la transgression, Genève, Droz (« Titre courant », 51), 2013, $19 \mathrm{~cm}, 376$ p., $26 €$, ISBN 978-2-600-00551-7.

1 Il pourrait paraître déplacé de recenser ici un recueil d'essais essentiellement consacrés à l'histoire de l'art, et en particulier à la question des "limites de la représentation » (p. 7). Deux des quatorze études qui composent le volume justifient pourtant un compte rendu.

2 La première s'interroge sur le «paradoxe de l'ange » dans une peinture telle que celle de Caravage qui se veut le «miroir de la réalité » («Les anges du Caravage », p. 75-99). En analysant les chefs-d'œuvre crées par l'artiste italien pendant sa première période romaine, l'A. montre comment Caravage utilise l'ombre «comme moyen de visualisation du sacré » (p. 88). Finalement, ce que les yeux hallucinés de la première version du saint Matthieu de la chapelle Contarelli regardent, ce sont moins les lettres hébraïques que l'ombre que jette le bras immaculé de l'ange s'interposant entre l'apôtre et la page de l'Évangile à écrire. Le clair-obscur se trouve ainsi mis au service d'un vaste questionnement qui porte sur la figurabilité du surnaturel, qu'il agisse de la silhouette majestueuse projetée sur l'écran d'un mur - une sorte de divine lanterne magique - dans Les sept œuvres de Miséricorde ou de l'ombre portée, et dès lors porteuse d'une véritable présence, dans la Madone de Loreto ou dans Le souper d'Emmaüs. La fonction de l'ombre en tant que "principe de réalité " s'articule ainsi, dans un jeu d'intégrations et d'oppositions savamment orchestrées par Caravage, avec le nuage, " principe d'irréalité » (p. 90) car « diaphragme symbolique entre ciel et terre » (p. 77). Ce qui permet à l'artiste d'exhiber en même temps l'irruption du sacré dans le monde 
d'ici-bas et la possibilité d'une sacralisation de ce qu'il a de plus profane, jusqu'à utiliser le même modèle pour un des Tricheurs de Fort Worth et pour l'ange doucement serpentin du Repos de la fuite en Égypte de la Galerie Dora Pamphilj.

3 C'est un semblable chassé-croisé du sacré et du profane, sinon du théologique et du politique qui est au centre aussi de la dernière étude reprise ici par l'A., « La chute des idoles» (p. 347-357). Un souvenir d'enfance lié à la disparition inopinée dans l'espace d'une nuit de l'immense statue en bronze de Staline qui trônait dans le Jardin Public de Bucarest devient l'occasion d'une réflexion sur la logique profonde du démantèlement des images de pouvoir. D'où, d'une part, un constat: celui de la «permanence d'une structure rituelle inébranlable» (p.351) qui rapproche les pratiques d'iconoclasme anciennes et bibliques des vandalismes qui suivirent la chute des régimes totalitaires $\mathrm{du} \mathrm{Xx}$ siècle ("remplacement, changement de lieu, déroulement secret et nocturne »). Et l'A. de préciser avec finesse que dans un cas comme dans l'autre, l'enjeu est moins celui d'une punition symbolique que la volonté de désamorcer le pouvoir d'une image qui a la force d'une idole. D'autre part, la réflexion sur les pratiques de démantèlement débouche sur la nécessité, pour l'art d'élaborer, une « critique active » des simulacres, autant ceux déjà brisés que ceux qui se hissent encore sur leurs socles. Les deux exemples évoqués par l'A., une installation de K. Bednarski (Total portrait of Marx, 1978) et les photos documentant l'installation du Marx-Engels-Denkmalanlage par S. Bergmann (1986) sont d'autant plus remarquables que leur mélange de critique, d'objectivité et d'ironie annonce la voie suivie encore aujourd'hui par les artistes confrontés à la violence des régimes. Avec ces deux études, le volume apporte une contribution intéressante au débat sur le rapport entre fonction sacrée de l'image et logique de la représentation, un thème auquel la «visual culture » des dernières années a toujours accordé une attention privilégiée.

\section{AUTEURS}

\section{ALBERTO FRIGO}

Université Lyon 2. 